\title{
Improving care in surgery - a qualitative study of managers' experiences of implementing evidence-based practice in the operating room
}

\author{
Annette Erichsen Andersson ${ }^{* 1,2}$, Wendy Gifford ${ }^{3,4}$, Kerstin Nilsson ${ }^{1}$ \\ ${ }^{1}$ University of Gothenburg, The Sahlgrenska Academy, Institute of Health and Care Sciences, Gothenburg, Sweden \\ ${ }^{2}$ The Swedish Institute for Health Science, Lund, Sweden \\ ${ }^{3}$ Univeristy of Ottawa, Ottawa, Ontario, Canada \\ ${ }^{4}$ Saint Elizabeth Health Care, Markham, Ontario, Canada
}

Received: April 7, 2015

DOI: $10.5430 /$ jha.v4n4p73
Accepted: May 10, 2015

Online Published: May 18, 2015

\begin{abstract}
Background: More knowledge is needed on the preconditions and circumstances for leading implementation of evidence based practice in the operating room (OR). Effective leadership support is critical to enhance the provision of safer care. The aim of this study was to explore managers' and clinical leaders' experiences of implementing evidence-based practice to increase patient safety in the operating room.

Methods: The study had a qualitative descriptive design. In all, 25 managers were interviewed, with different surgical specialities (orthopedics, general and pediatric surgery) and operating room suites, from eight hospitals and 15 departments.

Results: The organizational structures were defined as key obstacles to implementation. Specifically, lack of a common platform for cooperation between managers from different departments, organizational levels and professional groups impeded the alignment of shared goals and directions. In cases where implementation was successful, well-functioning and supportive relationships between the managers from different professions and levels were crucial along with a strong sense of ownership and control over the implementation process. Whilst managers expressed the conviction that safety was an important issue that was supported by top management, the goal was usually to "get through" as many operations as possible. This created conflicts between either prioritizing implementation of safety measures or production goals, which sometimes led to decisions that were counter to evidence-based practice (EBP). While evidence was considered crucial in all implementation efforts, it might be neglected and mistrusted if hierarchical boundaries between professional subgroups were challenged, or if it concerned preventive innovations as opposed to technical innovations.

Conclusions: The preconditions for implementing EBP in the OR are suboptimal; thus addressing leadership, organizational and interprofessional barriers are of vital importance.
\end{abstract}

Key Words: Leadership, Operating room, Implementation, Evidence-based practice, Knowledge translation

\section{INTRODUCTION}

It is estimated that 234 million major surgical procedures are undertaken worldwide annually. ${ }^{[1]}$ The implementation of innovations for surgical care within the operating room (OR) context has been massive over the last 100 years and can be described in many ways as a life-saving success. How-

\footnotetext{
*Correspondence: Annette Erichsen Andersson; Email: annette.erichsen.andersson@ gu.se; Address: Institute of Health and Care Sciences, Box 457, 40530 Gothenburg, Sweden.
} 
ever, unintended harm from surgery such as postoperative infections are preventable complications that cause unnecessary patient suffering ${ }^{[2-4]}$ and deaths. ${ }^{[5,6]}$ Results from the Harvard Medical Practice Study II ${ }^{[7]}$ showed that nearly half $(48 \%)$ of the errors in medical practice were related to surgical procedures, most of which occurred in the OR. Out of these $74 \%$ were considered to be preventable. Numerous more recent studies ${ }^{[6,8,9]}$ are consistent with these results showing that adverse events affected nearly $10 \%$ of hospitalized patients and that most of these were related to intraoperative management. Deficits related to both technical and non-technical skills played important roles ${ }^{[10,11]}$ and the lack of teamwork as well as failures in communication and decision-making have been associated with technical errors in surgery. ${ }^{[12-15]}$ Preventive innovations such as the correct timing, type and dose of prophylactic antibiotics have in many cases been reported to be suboptimal. ${ }^{[16-19]}$ In addition, ample evidence exists for deficits in hand hygiene during anesthetic care, ${ }^{[20-24]}$ intraoperative patient warming during surgery, ${ }^{[19]}$ and restricted traffic flow during surgical procedures. ${ }^{[25-28]}$ These results show a substantial "knowdo gap" [29] between what is known about safe and effective practice and what is actually done in the OR, supporting an urgent need for implementing evidence-based practice for preventive innovations in order to enhance the safety of patients.

In the field of implementation science, much effort has been invested in identifying explanatory factors for the successful implementation of research-based innovations. ${ }^{[30,31]}$ This has proven challenging as all implementation occurs within a specific context and culture which influences outcome. Understanding the outer and inner context of the environment is emphasized in frameworks that define determinants important for implementation. ${ }^{[32-36]}$ Other critical factors mentioned are characteristics of the innovation/guidelines, the users of the innovation, and the implementation strategy. Barriers to successful implementation of evidence-based practice (EBP) in the OR have been described in recent years especially in relation to the implementation of the World Health Organization (WHO) surgical safety checklist, ${ }^{[37]}$ but also the implementation of safe communication and teamwork. $^{[38-44]}$ Barriers identified in these studies and many others are lack of leadership and management support on various levels. Other barriers were ambiguous goal setting, lack of effective implementation strategies, senior clinicians resistant to change and hierarchical structures (ibid). With lack of effective leadership and management support consistently described, there is a growing interest in understanding the role of leadership in implementing EBP. ${ }^{[45]}$ While barriers and facilitators to guideline use and EBP have been extensively studied for physicians ${ }^{[46]}$ nurses $^{[34,47-49]}$ and other healthcare providers, ${ }^{[50]}$ no studies were found that focused on implementation EPB from the perspective of managers and leaders in the OR context. Thus, more knowledge is needed on the preconditions and circumstances for leading the implementation of EBP in the OR and how effective leadership support can be tailored to enhance the provision of safer care.

The aim of the study was to explore managers' and clinical leaders' experiences of implementing evidence-based practice to increase patient safety in the OR and inform a future intervention trial.

The following research questions guided the study:

- What rationales inform managers' choice to address an identified know-do gap?

- How do managers and clinical leaders describe preconditions for implementing EBP in the OR?

\section{Methods}

A qualitative descriptive design was chosen as the purpose was to acquire a deep understanding of the preconditions for implementation from the perspective of managers and clinical leaders, and there is limited knowledge in this field.

\subsection{Participants}

We chose not to distinguish between managers and clinical leaders, as leadership is recognized as vital to both roles. ${ }^{[51]}$ Hence managers and clinical leaders will subsequently be referred to collectively as managers. Managers of surgical specialities (orthopedics, general and pediatric surgery) and operating room units/suites from eight hospitals and 15 departments in south and mid-Sweden were identified through hospital homepages. Participants were strategically selected with regard to age, gender, experience, professional status and level of management to ensure a variety of experiences in concordance with the qualitative approach. Managers were subsequently contacted by phone and asked if they would like to take part in the study. Interested parties were sent written information describing the study procedures that included participation in a face-to-face interview to recount their experiences of leading the implementation of EBP in the OR, with a focus on patient safety. In all, 25 managers were interviewed to ensure variation. The interviews lasted 45-90 minutes and were conducted and recorded in the managers' offices. The median age of participants was 54 (range 40-63), with 15 females and 10 males, 12 RNs and 13 physicians. Participating heads of department were all physicians ( 2 females and 4 males); OR managers were all registered nurses (RN) (10 females and 2 males). Two healthcare developers were included as well as seven clinical chief physicians. 
The managers' leadership experiences varied from 1 to 30 years, with a median length of 13 years, see Table 1 for demographic data.

Table 1. Basic demographics of the 25 participating managers

\begin{tabular}{lll}
\hline Participant & Varieties & Number \\
\hline & Orthopedics & 14 \\
Speciality/OR & General surgery & 6 \\
& Pediatric surgery & 3 \\
& Mixed types of surgeries & 2 \\
Years in profession, & Physicians & $29(7-42)$ \\
median (min-max) & Registered Nurses & $30(10-40)$ \\
& Head of department & 6 \\
Number and type of & OR manager & 10 \\
managers included & Healthcare developer & 2 \\
& Clinical chief physician & 7 \\
Academic degree: & Bachelor degree & 2 \\
Registered Nurses & PhD & 1 \\
Academic degree: & PhD & 8 \\
Physicians & & \\
\hline
\end{tabular}

\subsection{Data collection and analysis}

All interviews started with the same question: "Can you please tell me about a situation were you have been leading the implementation of any kind of evidence based practice to enhance patient safety in the OR? You can choose to describe a situation that you think was successful or that failed or were difficult, or both if you like". Managers were encouraged to freely narrate their experiences. Follow-up questions were raised to probe deep descriptions, for example questions such as: "can you describe that in more detail”, or "can you explain?” Interviews were transcribed verbatim and analyzed using thematic content analysis as described in Miles \& Hubermann. ${ }^{[52]}$ The texts were read and reread to gain a sense of the whole. We started the analytic process by identifying meaning units and giving the units descriptive codes. The next step consisted of comparing the similarities and differences of the codes with the meaning units included in them and grouping them in relation to their contents. In further analysis, groups of similar content were formed into subthemes and thematic dimensions expressing the underlying content of the text. Two researchers (AEA and $\mathrm{KN}$ ) coded all the texts separately and the codes and themes were discussed until consensus was reached. A third researcher (WG) participated in assessing the credibility and confirmability of the results. ${ }^{[53]}$

\subsection{Ethics}

The study followed the declaration of Helsinki; ${ }^{[54]}$ the interviewees were informed about the study, confidentiality was guaranteed and informed consent was obtained. All interviewees were given the opportunity to partake of the results before publication.

\section{RESULTS}

Since participants could freely choose the EBP episode they narrated, the data included a variety of subjects (see Table 2).

Table 2. The type of evidence based innovations and other changes initiatives that the informants prioritized to talk about

\begin{tabular}{lc} 
Type of evidence-based innovation that was implemented & $\begin{array}{l}\text { Number of interviews } \\
\text { where the particular } \\
\text { innovation was highlighted }\end{array}$ \\
\hline $\begin{array}{l}\text { Innovations preventing infection targeting: central line infections, urinary tract infections, post-operative wound } \\
\text { infections, hand hygiene and air cleanliness in the OR }\end{array}$ & 12 \\
The WHO Safer Surgery Checklist - teamwork and communication & 10 \\
Perioperative pain, nausea and iv. fluid management & 5 \\
Introducing a new kind of surgical method & 1 \\
Prevention of pressure ulcers & 1 \\
Other change initiatives & 3 \\
Major organizational changes & 3 \\
Increased production/ effectiveness, turnovers and streamlining in the OR & 8 \\
Total & 40
\end{tabular}

The analysis resulted in 4 thematic dimensions and 10 subthemes describing the preconditions and circumstances that affected implementation of EBP in the OR from the perspective of middle- and first-line managers (see Figure 1). Detailed descriptions of the themes and subthemes and their

Published by Sciedu Press relation to each other are outlined below.

\subsection{Motivators for change of practice}

Patient safety and quality improvement initiatives involving implementation of EBP were mainly driven by decisions taken by the top management team or managers identify- 
ing evidence/practice gaps that increased risks for adverse events.

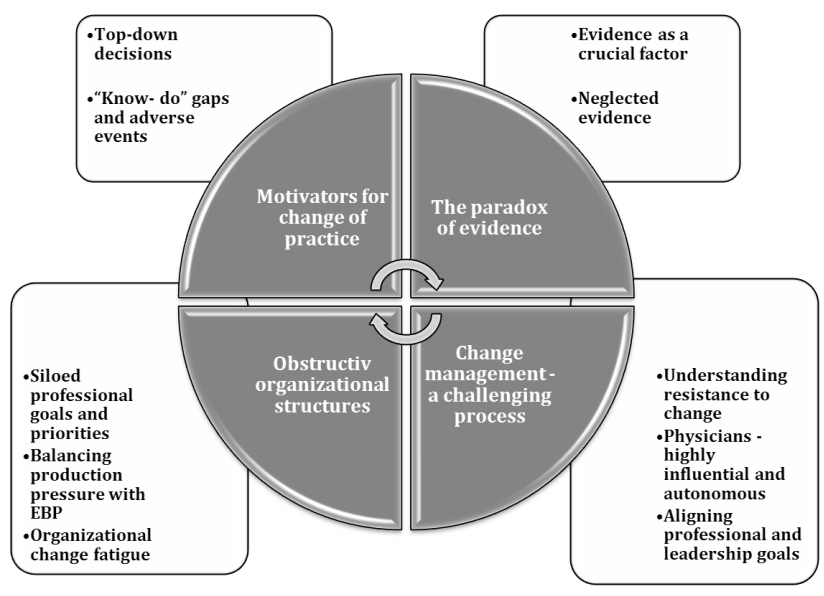

Figure 1. Themes and subthemes describing the preconditions for leadership and factors that affect implementation of evidence-based practice in the operating room

\subsubsection{Top down decisions}

Top down initiatives concerned implementations of hand hygiene, the WHO Surgical Safety checklist and "Surgery within 24 hours" for persons with hip-fracture. One of the most common points of departure for initiating EBP change was reports from the hospital's own surveillance system of high rates of postoperative infection: "Then the orthopedists in their turn said that there was a lot of concern about infections, since the figures were absolutely appalling."

\subsection{2 “Know-do" gaps and adverse events}

Managers described their own reactions to detecting poor quality of care through registry data or observations motivated them to implement EBP change. "And there wasn't any kind of care plan for alleviating the patient's symptoms, such as pain, nausea or postoperative mobilization. I wanted some kind of change."

Tragic events that resulted in patient deaths or permanent injuries were however the strongest motivator for implementing EBP. Several managers of surgical departments expressed frustration at not having a mandate to initiate and drive the implementation of EBP after they had identified needs for improved care in the OR: "We (the surgeons) do not have ownership of the OR, we are only seen as guests that have to adapt to the circumstances."

\subsection{The paradox of evidence}

The evidence in support of practice change was identified as the most important factor in order to succeed in changing practice. However, managers consistently described how evidence was challenged, depending on who presented the knowledge, and even neglected in relation to technical innovations.

\subsubsection{Evidence as a crucial factor}

The evidence base for what should be implemented was identified by all managers as one of the most or the most crucial factors for the willingness to adopt a new practice or to change behavior. It was seen as a tool for motivating physicians: "The doctors ask for and demand evidence." This was also true for nursing staff, especially nurses with an academic qualification. Nonetheless, nurses were sometimes described as "not being so interested in research-based knowledge". The lack of scientific training among nurses was recognized as a problem for two reasons. First, if nurses do not know how to understand the evidence for change, they are less likely to perceive the implementation as meaningful or motivating. Second, even if nurses are enthusiastic about implementing EBP, they find it difficult to convince physicians to change practice without engaging in scientific rhetoric of which they don't have the required training. For example, OR managers talked about difficulties in implementing infection control measures, and despite ample high quality evidence, physicians challenged the evidence with disbelief: "the doctors don't believe the data on hand hygiene." Several managers stated that it was difficult to argue the need for these innovations as they "lack the necessary knowledge about the evidence base".

\subsubsection{Neglected evidence}

Nurse managers in the OR expressed the conviction that hierarchical boundaries and differences in professional groups' knowledge base made management difficult, even if they had a strong evidence base to inform change. One manager stated that it was sometimes "like a game of power" where certain persons assumed the right to define which knowledge and evidence are of importance and worth considering. When OR nurses tried to implement the WHO Safer Surgery checklist, they were met with massive resistance from surgeons despite support from their OR manager and the strong evidence base that the checklist effectively decreased adverse events. Thus, implementation failed. However, after a series of adverse events, a surgeon took an interest in the checklist and promoted its use among peers and OR nurses. The checklist was positively received and successfully implemented, and the manager concluded that implementation of EBP is more likely to succeed if initiated by a physician with peer influence.

New technical innovations are usually met with interest by nurses and physicians as they are seen as fun and a challenging part of the job. Evidence in favor of the new method 
is rarely asked for, and as more than one manager stated: "these changes are sometimes implemented too easily and too quickly from a safety perspective." For implementation of new operating methods or technical innovations, welldescribed and internalized procedures exist regarding how these are to be implemented. Specifically, the implementation procedures define who is responsible for the logistics, and how and when nurses are to be educated for using a particular method or tool. In contrast, no predefined pathway existed on how to implement "soft" innovations that, for example, target the behaviors of healthcare workers.

Sometimes new drugs or induction methods could also be a challenge to introduce especially with senior physicians: "arguments based on best evidence simply do not get through." However managers were reluctant to confront senior physicians out of respect to their status: "We will have to wait until they retire." Some managers also tried to understand senior physicians' resistance and neglect of evidence, recognizing the need to operate within an established "comfort zone" and the difficulties people may have in adopting new things: "as a doctor you want to do the things you feel sure about and know you do well."

Managers also expressed distrust in the evidence that had informed some of the decisions taken by senior managers: "There are pretty much quality improvement projects going on that at some point had a scientific base, like the WHO checklist." Now I haven't read up that much on all these studies, but when the WHO study was done under the conditions prevalent then, what it showed was scientifically correct, but I wonder how much it really improves how we care for our patients nowadays." and "In the end good initiatives tend to be submerged by the many strange decisions made by superiors" and "the evidence base is so far from our reality - or is it even applicable to us or only waste of time?"

\subsection{Obstructive organizational structures}

Managers identified hospital organizational structures as being a major obstacle for implementing EBP. Structures such as strong boundaries between departments involved in the care of the same patients were seen as important reasons for failures as they complicated dialogue, cooperation and goal alignment between managers and staff within and across departments and levels.

\subsubsection{Siloed professional goals and priorities}

Nurses, anesthesiologists and surgeons usually belonged to separate departments and thus had different managers, see Figure 1 for an empirical example. Managers recognized that one of the major obstacles to change that required participation of the whole team was that they only had the mandate

Published by Sciedu Press to target their own staff: "Why should we bother doing this if the doctors don't care?" They pointed out that different managers each had their own goals and priorities. These were not necessarily known to the other managers or aligned with the goals within and between department and hospital levels: "What we haven't succeeded in doing is cooperating with the orthopedists and providing information that arrives at the right time, is sufficient or at least adequate. That is to say information from another professional group not working in the same clinic..."

The majority of managers expressed the view that the absence of a well-needed common platform where managers from different departments could meet and discuss issues hindered their ability to work together across departmental boundaries: "We (clinical physician leaders of anesthesia and orthopedics) never meet and do any good planning together. They don't even seem to be interested, but maybe it is due to lack of time..."

\subsubsection{Balancing production pressure with EBP}

The daily focus managers described were what they called "production" - i.e. doing as many operations as possible and ensuring accurate staffing levels. Much of their energies were directed towards coping with stress, lack of time and staffing problems, rather than considering implementation of innovations. Whilst managers expressed the conviction that safety was an important issue that was supported by top management, the overarching goal was usually defined as "getting through" as many operations as possible. This created a conflict between prioritizing about safety measures or production goals, which sometimes lead to decisions that countered EBP. In particular, OR managers felt abandoned, expressing uncertainty as to whether or not the decisions taken were in line with best evidence. They also doubted if they have the mandate or the competence to take such a decision: "... One has a system demanding rapid turnovers which then collide with patient safety guidelines. And then as manager I'm the only one who can make a decision ... there's nobody standing by my side." Orthopedists who should be very interested should put their foot down and say that this is how things are. "The department of Infection Control don't say anything either. I think ... that it's difficult..." Not all managers shared this experience; others found no conflicts between safety and production goals.

Finding time for managing EBP change in the OR was usually challenging. One manager explained that he/she had tried unsuccessfully for years to get permission from top management to bring the OR staff together at least once a week for a team meeting to create the foundation for an implementation process. However, OR production pressures 
meant there was lack of time to engage in implementation work: “We've got a lot going on, and a lot of what we do is focused on production, and the strongest driving force has of course been rapid turnovers ..."

\subsubsection{Organizational change fatigue}

The narratives concerning organizational change were similar in that they described how the intended changes were meant to increase efficacy. Frequently however, the changes resulted in unforeseen negative consequences for patients. In one case this meant a 12 -fold increase of surgical site infection. Thus, it was felt that previous successful implementation of EBP and years of hard work could be dissolved within a few weeks due to reorganizations. The perception of several reorganizations and change processes that were seen as unimportant to the care of patient resulted in staff experiencing "organizational change fatigue". This was a strong counterweight towards all types of initiatives towards implementing EBP.

\subsection{Change management $\mathbf{- a}$ challenging process}

This thematic dimension comprised managers' understanding of resistance to change, and how to overcome these challenges.

\subsubsection{Understanding resistance to change}

Managers most commonly perceived co-workers' resistance as a natural way to react towards change. Resistance was recognized as something that is often rooted in emotions. As one manager said: "The resistance is not based on lack of evidence, but rather on feeling and mere assumptions, even in cases when a more academic standpoint could be expected."

Moreover, resistance and adoptions were often identified as person-bound. However, if several individuals in a group joined forces then the resistance might be strengthened and increased. Some managers saw resistance and questioning as both challenging and stimulating: "You need resistance to change, you need resistance to change otherwise it means that a complete organization has stopped thinking, but (as manager) you need the ability to address it."

The opposite view of co-workers' resistance to change was also expressed. Individuals and groups questioning decisions were experienced as difficult to handle and tiresome. "They must learn to understand that this is a management decision that can't be questioned" and "this is not a democratic organization where everyone has got to have their say."

The majority of managers found it difficult to understand why employees did not do what they were expected or had agreed to do. However, difficulties in recruiting staff was the reason mentioned that made it difficult to take on a tough attitude towards difficult people out of fear of losing personnel.

\subsubsection{Physicians - highly influential and autonomous}

Managers at all levels stated that physicians were particular hard to lead in change initiatives as they have a long tradition of autonomy, thus "they don't like to be told what to do".

Lack of cooperation and engagement from physicians was defined as a major obstacle to implementation, a typical statement being "we need to get the doctors on the train, if we want to succeed". Anesthesiologists and surgeons were recognized as important role models for the nurses, and if these doctors did not for example take hand hygiene seriously, then the managers would have difficulties in motivating others to change their practice.

\subsubsection{Aligning professional silos and leadership goals}

Successful implementation processes were seldom talked about, but those described were strikingly similar. They were all initiated as research projects by clinical chief physicians in close cooperation with OR managers. The well-functioning relationships between the different managers were defined as important and as a source of mutual support.

These managers described that they had a stable nursing staff that was engaged in all parts of the research process together with physicians, from data collection to presenting the results. The wards where the implementation had succeeded were relatively small, and this was seen as a fundamental factor for the positive outcome: "In a small group you tend to realize that what you do matters; people take on a responsibility”. The importance of visible leadership, communication and cooperation in order to create common goals between different professional categories was emphasized. The research-based interventions approach allowed for the direct feedback of results to participating staff and the positive effects for the patients created feelings of pride towards their efforts. Successful implementation was said to require time, patience and endurance. Struggling with failed implementation over long periods of time was common among managers, and this created feelings of resignation, aloneness, tiredness and most of all, frustration.

\section{Discussion}

This study was based on interviews with 25 managers with over 278 years of accumulated management experience. Thus our results provide novel information on how chief physician and nurse managers experience and understand the preconditions and circumstances that influence implementing EBP in the OR. The study contributes new knowledge on how organizational systems, subcultures and system ambiguities work as obstacles to EBP implementation. Moreover, the complexity of how evidence-based knowledge is perceived and valued, and the influence of power and hierarchies are 
revealed and highlighted. The thematic dimension resulting from the analysis is discussed in relation to Edgar Schien's theories on "Organizational Culture and Leadership". [55]

Managers in this study were given the possibility to talk about different kinds of EBP implementation and received both written and oral information about the focus on patient safety. It is reasonable to assume that they talked about situations that they remembered and that had some deeper meaning to them, ${ }^{[56]}$ and this could be interpreted as reflecting what managers pay attention to, value or are preoccupied with at the time. How managers' prioritize implementation needs appears to influence how nurses and physicians value what is important within the organization. The priorities and goals of senior managers have been shown to influence the adoption of innovations, ${ }^{[57,58]}$ and these directly influence and contribute to forming the culture in which they operate. Schein ${ }^{[59]}$ identified leaders' focus and priorities as "primary embedding mechanisms" and if used consciously, they are powerful tools to forward change. Equally, these mechanisms also work the opposite way by sending strong messages about what is not a priority through the things managers do not pay attention to or even ignore, ${ }^{[59,60]}$ underscoring the importance of communicating the embedded messages within a unit.

In this study, twelve managers talked about implementing innovations to prevent infections and the majority expressed uncertainties about addressing this issue because of the evidence base to support an innovation. Thus the message sent implicitly to staff was often ambiguous. The absence of a clearly defined message and the managers' commitment and communication to support the message could impede the implementation process. ${ }^{[51,61]}$ Managers expressed the conviction, for example, that hand hygiene was important. Yet while this was their espoused belief, it was not necessarily congruent with assumptions of what really mattered in the OR such as production pressures for increased OR volume. As shown in other studies, ${ }^{[62,63]}$ managers who expressed negative feelings about decisions made by senior management for implementing new initiatives, might unconsciously hinder these initiatives, despite their intention to hide their thoughts. Taken together, this ambiguity could possibly contribute to understanding why so many implementation initiatives were perceived as failures.

Aaron et al. ${ }^{[60]}$ point out that senior leaders need to understand the importance of involving front line and middle managers in dialogues concerning strategic goals in order to secure their understanding of and motivation for future execution. ${ }^{[64]}$ In addition, the crucial role of clinical leaders in change processes requires dedicated attention. ${ }^{[65]}$
One of the most important findings in our study was how the organization itself and internal professional structures work as significant obstacles to change processes. The importance of interdisciplinary priorities and goal setting were identified by managers in the OR as necessary for successful implementation. This is consistent with leadership research that identifies the importance of having a common goal and direction which are necessary for influencing others. ${ }^{[60]}$ The lack of regular and scheduled meetings impeded dialogue and cooperation between managers across departments which can lead to different priorities and goals being expressed to different professional groups within the OR team. These differing messages can thus influence what nurses and physicians pay attention to and perceive as important. A differentiated professional team will most likely contribute to strengthening the formation of subcultures and differentiated professional values. This might well obstruct interprofessional learning and effective teamwork ${ }^{[66,67]}$ and as shown in this study, impede the implementation of EBP in the OR and hinder the development of well-functioning teams. ${ }^{[55]}$ Previous research has showed that lack of teamwork, safe communication and shared goals as well as aggressive behavior are common in the OR and can negatively affect the safety of patients. ${ }^{[13,15,68,69]}$ To align and create congruent team goals, directions and missions between different managers and departments must be seen as the basis for the implementation of EBP in the OR, where in fact all care procedures are carried out by multi-professional teams.

In addition to organizational obstacles to implementation, hierarchies were found to hinder safe care and to obstruct the use of research-based knowledge. Even though hierarchies can provide stability and a sense of security within a group, they can also be counterproductive. ${ }^{[70]}$ The present study showed that power differences between nurses and physicians impeded knowledge sharing and contributed to creating risk-filled situations for patients in the OR. Sometimes knowledge brought forward by nurses was not regarded as valid or important despite the strength of the evidence. This finding is in line with theory defining learning and knowledge as a social construct, where group members with power define what should be seen as the "truth" and the knowledge that is important and worth paying attention to. ${ }^{[71]}$ Within the patient safety movement, health care practices that evolve within a culture of individualism, autonomy and hierarchal authority can create obstacles for safer care and effective teamwork. ${ }^{[72]}$ In order to overcome obstacles to EBP in the OR, basic assumptions regarding professional identity, authority and knowledge must be challenged and replaced by more appropriate assumptions such as interdependent collaboration, open communication, shared decision-making and 
leadership inclusiveness. ${ }^{[73,74]}$ Schein $^{[55]}$ reveals that challenging basic assumptions that offer meaning and stability can unleash anxiety and, rather than tolerate elevated anxiety levels, team members will strive to maintain equilibrium even if it means distorting, denying or falsifying. Leaders therefore need to be aware of the necessity and possibilities of creating a learning environment that supports and rewards staff's learning as well as interprofessional learning and relearning in a psychologically safe environment. ${ }^{[75-77]}$

An interesting finding of the present study was that technical innovations were received with enthusiasm and the ways of integrating these innovations were well established with minimal sources for conflict, in contrast to preventive innovations. Characteristics of preventive innovations, in contrast to other innovations, have been described by Rogers ${ }^{[30,78]}$ as new ideas that require action at one point in time to avoid unwanted consequences at some future time. Amongst other things, Rogers suggests that the degree of adoption can be explained by the relative advantage of the innovations - e.g. the new idea/practice has to be perceived as better than the old. The negative consequences of non-application of safe $\mathrm{HH}$ practice will not affect all patients and, when they do, symptoms of infection typically occur after the patients have left the OR. Thus the negative consequence of lack of EBP seldom becomes evident for the OR team. ${ }^{[78]}$ On the other hand, the steady stream of technical innovations in the OR seems to be an indisputable part of the culture.

\section{Strengths and limitations}

This study has limitations, for instance the qualitative approach did not allow for a large sample size. By using a survey with pre-define questions we could reach more participants, however the qualitative approach of the present study with open-ended questions allowed for a deeper insight into the perspectives of healthcare managers on the implementation of EBP. This would not have been possible using a quantitative method.

In data collection and the during analysis, measures were taken to achieve trustworthiness, such as careful selection of participants with various experiences, the selection of meaning units in line with the intended focus of the study, and seeking agreement regarding thematic dimensions among co-researchers. ${ }^{[53]}$ To enhance credibility, results were sup- ported by representative quotes from the transcribed interviews. Further ethnographic studies in this setting would be complementary and could provide valuable insight into what really goes on in the OR. This new knowledge can be used by leaders to deliberately reconstruct assumptions that are no longer valid or even contraproductive for the survival of the group. Future studies should also focus on managers' understanding of their role as leaders and the use of implementation strategies.

\section{Conclusions}

Resistance was understood as a natural way for co-workers to react to change, and it was often rooted in emotions. While evidence was a crucial component in all implementation efforts, hierarchical boundaries between professional groups and subgroups often led to it being neglected and mistrusted. Organizational systems and structures were key obstacles to implementing evidence-based practice in the OR, specifically lack of a common platform for communication and cooperation between managers of different departments and professional groups impeded the alignment of shared goals and directions. In cases where implementation was successful, well-functioning and supportive relationships between the managers of different professions and organizational levels were crucial, along with a strong sense of ownership and control over the implementation process. The preconditions for implementing EBP in the OR are suboptimal; thus addressing leadership as well as organizational and interprofessional barriers are of vital importance.

\section{Authors' contribution}

AEA: designed the study and obtained funding, conducted the interviews, prepared the manuscript and analysed data. WG: participated in the interpretation of the analysis and the preparation of the manuscript. KN: participated in designing the study, data analysis and the preparation of the manuscript. All authors read, revised, and approved the final manuscript.

\section{ACKNOWLEDGEMENTS}

We would like to thank all participants for generously sharing their experiences. The Swedish Institute For Health Sciences funded the study.

\section{CONFLicts OF InTEREST Disclosure}

The authors declare that they have no competing interests.

\section{REFERENCES}

[1] Weiser TG, Regenbogen SE, Thompson KD, et al. An estimation of the global volume of surgery: a modelling strategy based on available data. Lancet. 2008; 372(9633): 139-44. http://dx.doi.org/10. $1016 / \mathrm{S} 0140-6736(08) 60878-8$

[2] Swenne CL, Skytt B, Lindholm C, et al. Patients' experiences of 
mediastinitis after coronary artery bypass graft procedure. Scand Cardiovasc J. 2007; 41(4): 255-64. http://dx.doi.org/10.10 80/14017430701283856

[3] Tanner J, Padley W, Davey S, et al. Patient narratives of surgical site infection: implications for practice. J hosp infect. 2013; 83(1): 41-5. http://dx.doi.org/10.1016/j.jhin.2012.07.025

[4] Andersson AE, Bergh I, Karlsson J, et al. Patients' experiences of acquiring a deep surgical site infection: An interview study. Am J of Infect Control. 2010; 38(9): 711-7. PMid: 21034980. http://dx.doi.org/10.1016/j.ajic.2010.03.017

[5] WHO. Safe Surgery. World Health Organization, Geneva, Switzerland. 2014. Available from: http://www. who.int/patientsaf ety/safesurgery/en/. Accessed October 1, 2014.

[6] de Vries EN, Ramrattan MA, Smorenburg SM, et al. The incidence and nature of in-hospital adverse events: a systematic review. Qual Saf Health Care. 2008; 17(3): 216-23. http://dx.doi.org/10. 1136 /qshc. 2007.023622

[7] Leape LL, Brennan TA, Laird N, et al. The nature of adverse events in hospitalized patients. Results of the Harvard Medical Practice Study II. N Engl J Med. 1991; 324(6): 377-84. http: //dx.doi.org/10.1056/NEJM199102073240605

[8] Gawande AA, Thomas EJ, Zinner MJ, et al. The incidence and nature of surgical adverse events in Colorado and Utah in 1992. Surgery. 1999; 126(1): 66-75. http://dx.doi.org/10.1067/msy. 1999. 98664

[9] Vincent C, Aylin P, Franklin BD, et al. Is health care getting safer? BMJ. 2008; 337: a2426. PMid: 19008272. http://dx.doi.org/1 $0.1136 / \mathrm{bmj} . \mathrm{a} 2426$

[10] Greenberg CC, Regenbogen SE, Studdert DM, et al. Patterns of communication breakdowns resulting in injury to surgical patients. J Am Coll Surg. 2007; 204(4): 533-40. http://dx.doi.org/10.1016 $/ j$.jamcollsurg. 2007.01.010

[11] Regenbogen SE, Greenberg CC, Studdert DM, et al. Patterns of technical error among surgical malpractice claims: an analysis of strategies to prevent injury to surgical patients. Ann of surg. 2007; 246(5): 705-11. http://dx.doi.org/10.1097/SLA.0b0 $13 \mathrm{e} 31815865 f 8$

[12] Hull L, Arora S, Aggarwal R, et al. The impact of nontechnical skills on technical performance in surgery: a systematic review. J Am Coll Surg. 2012; 214(2): 214-30. http://dx.doi.org/10.1016/j.j amcollsurg.2011.10.016

[13] Catchpole K, Mishra A, Handa A, et al. Teamwork and error in the operating room: analysis of skills and roles. Ann surg. 2008; 247(4): 699-706. http://dx.doi.org/10.1097/SLA.0b013e3 181642 ec8

[14] Lingard L, Regehr G, Orser B, et al. Evaluation of a preoperative checklist and team briefing among surgeons, nurses, and anesthesiologists to reduce failures in communication. Arch Surg. 2008; 143(1): 12-7; discussion 8. http://dx.doi.org/10.1001/arc hsurg. 2007.21

[15] Gillespie BM, Chaboyer W, Fairweather N. Interruptions and miscommunications in surgery: an observational study. AORN journal. 2012; 95(5): 576-90. http://dx.doi.org/10.1016/j.aorn. 20 12.02 .012

[16] Ozgun H, Ertugrul BM, Soyder A, et al. Peri-operative antibiotic prophylaxis: adherence to guidelines and effects of educational intervention. Int J Surg. 2010; 8(2): 159-63. http://dx . doi . org/10. $1016 / j . i j s u .2009 .12 .005$

[17] van Kasteren ME, Kullberg BJ, de Boer AS, et al. Adherence to local hospital guidelines for surgical antimicrobial prophylaxis: a multicentre audit in Dutch hospitals. J Antimicrob Chemother. 2003; 51(6): 1389-96. http://dx.doi.org/10.1093/jac/dkg264
[18] Stefansdottir A, Robertsson O, W-Dahl A, et al. Inadequate timing of prophylactic antibiotics in orthopedic surgery. We can do better. Acta Orthop. 2009; 80(6): 633-8. PMid: 19995312. http: //dx.doi.org/10.3109/17453670903316868

[19] Andersson AE, Bergh I, Karlsson J, et al. The application of evidencebased measures to reduce surgical site infections during orthopedic surgery - report of a single-center experience in Sweden. Patient Saf Surg. 2012; 6(1): 11. http://dx.doi.org/10.1186/1754-949 3-6-11

[20] Biddle C, Shah J. Quantification of anesthesia providers' hand hygiene in a busy metropolitan operating room: what would Semmelweis think? Am J Infect Control. 2012; 40(8): 756-9. http: //dx.doi.org/10.1016/j.ajic.2011.10.008

[21] Megeus V, Nilsson K, Eriksson B, et al. Hand hygiene and aseptic techniques during routine anesthetic care - observations in the operating room. Antimicrob Resist Infect Control. 2015; 4: 5 . http://dx.doi.org/10.1186/s13756-015-0042-y

[22] Krediet AC, Kalkman CJ, Bonten MJ, et al. Hand-hygiene practices in the operating theatre: An observational study. Br J Anaesth. 2011; 107(4): 553-8. PMid: 21665900. http://dx.doi.org/10.1093 /bja/aer162

[23] Rowlands J, Yeager MP, Beach M, et al. Video observation to map hand contact and bacterial transmission in operating rooms. Am J Infect Control. 2014; 42(7): 698-701. http://dx .doi .org/10.10 16/j.ajic.2014.02.021

[24] Loftus RW, Muffly MK, Brown JR, et al. Hand contamination of anesthesia providers is an important risk factor for intraoperative bacterial transmission. Anesthesia and analgesia. 2011; 112(1): 98-105. PMid: 20686007. http://dx.doi.org/10.1213/ANE.0b013e3 $181 \mathrm{e} 7 \mathrm{ce} 18$

[25] Andersson AE, Bergh I, Karlsson J, et al. Traffic flow in the operating room: An explorative and descriptive study on air quality during orthopedic trauma implant surgery. Am J Infect Control. 2012 http://dx.doi.org/10.1016/j.ajic.2011.09.015

[26] Lynch RJ, Englesbe MJ, Sturm L, et al. Measurement of foot traffic in the operating foom: Implications for infection control. Am J MedQual. 2009; 24(1): 45-52. PMid: 19139463. http: //dx.doi.org/10.1177/1062860608326419

[27] Panahi P, Stroh M, Casper DS, et al. Operating Room Traffic is a Major Concern During Total Joint Arthroplasty. Clin Orthop Relat Res. 2012. http://dx.doi.org/10.1007/s11999-012-2252-4

[28] Young RS, O'Regan DJ. Cardiac surgical theatre traffic: Time for traffic calming measures? Interactive Cardiovascular and Thoracic Surgery. 2010; 10(4): 526-9. PMid: 20100706. http://dx.doi.o $\mathrm{rg} / 10.1510 /$ icvts .2009 .227116

[29] Pablos-Mendez A, Shademani R. Knowledge translation in global health. J Contin Educ Health Prof. 2006; 26(1): 81-6. http://dx.d oi.org/10.1002/chp. 54

[30] Rogers E. Diffusion of Innovations. $5^{\text {th }}$ ed. New York: The Free Press; 2003.

[31] Grol R, Grimshaw J. From best evidence to best practice: effective implementation of change in patients' care. Lancet. 2003; 362(9391): 1225-30. http://dx.doi.org/10.1016/S0140-673 6 (03) 14546-1

[32] Damschroder LJ, Aron DC, Keith RE, et al. Fostering implementation of health services research findings into practice: a consolidated framework for advancing implementation science. Implement Sci. 2009; 4: 50. http://dx.doi.org/10.1186/1748-5908-4-50

[33] Flottorp SA, Oxman AD, Krause J, et al. A checklist for identifying determinants of practice: a systematic review and synthesis of frameworks and taxonomies of factors that prevent or enable im- 
provements in healthcare professional practice. Implement Sci. 2013; 8: 35. http://dx.doi.org/10.1186/1748-5908-8-35

[34] Grol R, Wensing H, Hulscher M, et al. Theories on implementation of change in healthcare. In: Grol R, Wensing H, Hulscher M, Eccles $\mathrm{M}$, editors. Improving patient care: The Implementation of Change in Clinical Practice. Edinburgh: Elsevier; 2005.

[35] Gurses AP, Marsteller JA, Ozok AA, et al. Using an interdisciplinary approach to identify factors that affect clinicians' compliance with evidence-based guidelines. Crit Care Med. 2010; 38(8 Suppl): S28291. http://dx.doi.org/10.1097/CCM.0b013e3181e69e02

[36] Rycroft-Malone J, Seers K, Chandler J, et al. The role of evidence, context, and facilitation in an implementation trial: implications for the development of the PARIHS framework. Implement Sci. 2013; 8 : 28. http://dx.doi.org/10.1186/1748-5908-8-28

[37] Haynes AB, Weiser TG, Berry WR, et al. A surgical safety checklist to reduce morbidity and mortality in a global population. N Engl J Med. 2009; 360(5): 491-9. http://dx.doi .org/10.1056/NEJ Msa0810119

[38] Conley DM, Singer SJ, Edmondson L, et al. Effective surgical safety checklist implementation. J Am Coll Surg. 2011; 212(5): 873-9. ht tp://dx.doi.org/10.1016/j.jamcollsurg. 2011.01.052

[39] Dackiewicz N, Viteritti L, Marciano B, et al. [Achievements and challenges in implementing the surgical checklist in a pediatric hospital]. Arch Argent Pediatr. 2012; 110(6): 503-8. http://dx.doi : 10.1590/s0325-00752012000600008

[40] Fourcade A, Blache JL, Grenier C, et al. Barriers to staff adoption of a surgical safety checklist. BMJ Qual Saf. 2012; 21(3): 191-7. http://dx.doi.org/10.1136/bmjqs-2011-000094

[41] Gillespie BM, Chaboyer W, Longbottom P, et al. The impact of organisational and individual factors on team communication in surgery: a qualitative study. Int J Nurs Stud. 2010; 47(6): 732-41. http://dx.doi.org/10.1016/j.ijnurstu.2009.11.001

[42] Kates SL, O'Malley N, Friedman SM, et al. Barriers to implementation of an organized geriatric fracture program. Geriatr Orthop Surg Rehabil. 2012; 3(1): 8-16. http://dx.doi.org/10.1177/21514 58512436423

[43] O'Connor P, Reddin C, O'Sullivan M, et al. Surgical checklists: the human factor. Patient Saf Surg. 2013; 7(1): 14. http://dx.doi.o $\mathrm{rg} / 10.1186 / 1754-9493-7-14$

[44] Russ SJ, Sevdalis N, Moorthy K, et al. A Qualitative Evaluation of the Barriers and Facilitators Toward Implementation of the WHO Surgical Safety Checklist Across Hospitals in England: Lessons From the "Surgical Checklist Implementation Project". Ann Surg. 2014. http://dx.doi.org/10.1097/SLA.0000000000000793

[45] Gifford W, Davies B, Edwards N, et al. Managerial leadership for nurses' use of research evidence: an integrative review of the literature. Worldviews Evid Based Nurs. 2007; 4(3): 126-45. http://dx.doi.org/10.1111/j.1741-6787.2007.00095.x

[46] Grol R. Successes and failures in the implementation of evidencebased guidelines for clinical practice. Med Care. 2001; 39(8 Suppl 2): II46-54. http://dx.doi.org/10.1097/00005650-200108002 $-00003$

[47] Jeffery AD, Pickler RH. Barriers to nurses' adherence to central venous catheter guidelines. J Nurs Adm. 2014; 44(7/8): 429-35. http://dx.doi.org/10.1097/NNA. 0000000000000094

[48] Dogherty EJ, Harrison MB, Graham ID, et al. Turning knowledge into action at the point-of-care: the collective experience of nurses facilitating the implementation of evidence-based practice. Worldviews Evid Based Nurs. 2013; 10(3): 129-39. http: //dx.doi.org/10.1111/wvn. 12009

[49] Forsman H, Rudman A, Gustavsson P, et al. Nurses' research utilization two years after graduation-a national survey of associated individual, organizational, and educational factors. Implement Sci. 2012; 7: 46. http://dx.doi.org/10.1186/1748-5908-7-46

[50] Ploeg J, Davies B, Edwards N, et al. Factors influencing best-practice guideline implementation: lessons learned from administrators, nursing staff, and project leaders. Worldviews Evid Based Nurs. 2007; 4(4): 210-9. http://dx.doi.org/10.1111/j.1741-6787.20 $07.00106 . x$

[51] Yukl G. Leadership in Organizations. $8^{t h}$ ed. Harlow, England: Pearsons Education Limited; 2012.

[52] Miles MB, Huberman AM. Qualitative Data Analysis An expanded Source-book. $2^{\text {nd }}$ ed. Thousand Oaks, Calif: Sage Publications; 1994. S0260691703001515 [pii].

[53] Graneheim UH, Lundman B. Qualitative content analysis in nursing research: concepts, procedures and measures to achieve trustworthiness. Nurse Education Today. 2004; 24(2): 105-12. http: //dx.doi.org/10.1016/j.nedt.2003.10.001

[54] World Medical Association. World Medical Association Declaration of Helsinki: ethical principles for medical research involving human subjects. JAMA : The Journal of the American Medical Association. 2013; 310(20): 2191. PMid: 24141714. http: //dx.doi.org/10.1001/jama.2013.281053

[55] Schein EH. Organizational Culture and Leadership. $3^{\text {rd }}$. ed. The Jossey-Bass Business \& Management Series. San Francisco: Wiley; 2004.

[56] Kvale S. Doing Interviews. $1^{\text {st }}$ ed. Thousand Oaks, California: SAGE Publications; 2007.

[57] Damanpour F. Organizational Innovation: A Meta-Analysis of Effects of Determinants and Moderators. Academy of Management Journal. 1991; 34(3): 555-90. http://dx.doi.org/10.2307/2 56406

[58] Gifford WA, Davies BL, Graham ID, et al. Developing leadership capacity for guideline use: a pilot cluster randomized control trial. Worldviews Evid Based Nurs. 2013; 10(1): 51-65. http: //dx.doi.org/10.1111/j.1741-6787.2012.00254.x

[59] Schein E. Organizational Culture and Leadership. The Jossey-Bass Business \& Management Series. Wiley; 2010.

[60] Aarons GA, Ehrhart MG, Farahnak LR, et al. Aligning leadership across systems and organizations to develop a strategic climate for evidence-based practice implementation. Annu Rev Public Health. 2014; 35: 255-74. http://dx.doi.org/10.1146/annurev-pub lhealth-032013-182447

[61] Nilsson K, Furåker C. Learning leadership through practice - healthcare managers' experience. Leadersh Health Serv. 2012; 25(2): 10622. http://dx.doi.org/10.1108/17511871211221037

[62] Guth WD, Macmillan IC. Strategy implementation versus middle management self-interest. Strategic Management Journal. 1986; 7(4): 313-27. http://dx.doi.org/10.1002/smj . 4250070403

[63] Jacobs JA, Dodson EA, Baker EA, et al. Barriers to Evidence-Based Decision Making in Public Health: A National Survey of Chronic Disease Practitioners. Public Health Rep. 2010; 125(5): 736-42. PMid: 20873290.

[64] Wooldridge B, Floyd SW. The strategy process, middle management involvement, and organizational performance. Strategic Management Journal. 1990; 11(3): 231-41. http://dx.doi.org/10.1002/s $\mathrm{mj} .4250110305$

[65] Ovretveit J, Andreen-Sachs M, Carlsson J, et al. Implementing organisation and management innovations in Swedish healthcare: lessons from a comparison of 12 cases. J Health Organ Manag. 2012; 26(2): 237-57. http://dx.doi.org/10.1108/14777261211230790

[66] Carroll JS, Quijada MA. Redirecting traditional professional values to support safety: changing organisational culture in health care BMJ 
Qual Saf. 2004; 13(suppl 2): ii16-ii21. http://dx.doi.org/10. 1136/qshc. 2003.009514

[67] Hall P. Interprofessional teamwork: professional cultures as barriers. J Interprof Care. 2005; 19 Suppl 1: 188-96. http://dx.doi .org /10.1080/13561820500081745

[68] Coe R, Gould D. Disagreement and aggression in the operating theatre. J Adv Nurs. 2008; 61(6): 609-18. http://dx.doi.org/10. $1111 / j .1365-2648.2007 .04544 . x$

[69] Rogers D, Lingard L, Boehler ML, et al. Teaching operating room conflict management to surgeons: clarifying the optimal approach. Med Educ. 2011; 45(9): 939-45. http://dx.doi.org/10.1111 /j.1365-2923.2011.04040.x

[70] Weller J, Boyd M, Cumin D. Teams, tribes and patient safety: overcoming barriers to effective teamwork in healthcare. Postgrad Med J. 2014; 90(1061): 149-54. http://dx.doi.org/10.1136/postg radmedj-2012-131168

[71] Berger P, Luckman T. The Social Construction of Reality A Treatise in the Sociology of Knowledge. London: Penguin Group; 1991/1966.

[72] Leape LL, Berwick DM. Five years after To Err Is Human: what have we learned? JAMA. 2005; 293(19): 2384-90. http://dx.doi
. org/10.1001/jama.293.19.2384

[73] Xyrichis A, Ream E. Teamwork: a concept analysis. J Adv Nurs. 2008; 61(2): 232-41. http://dx.doi.org/10.1111/j.1365-2 $648.2007 .04496 . \mathrm{x}$

[74] Nembhard IM, Edmondson AC. Making it safe: The effects of leader inclusiveness and professional status on psychological safety and improvement efforts in health care teams. Journal of Organizational Behavior. 2006; 27(7): 941-66. http://dx.doi.org/10.1002/j ob. 413

[75] Edmondson AC. Learning from failure in health care: frequent opportunities, pervasive barriers. BMJ Qual Saf. 2004; 13(Suppl 2): ii3-9. http://dx.doi.org/10.1136/qhc.13.suppl_2.ii3

[76] Edmondson AC. The competitive imperative of learning. Harv Bus Rev. 2008; 86(7-8): 60-7, 160. PMid: 18681298.

[77] Edmondson AC. Strategies of learning from failure. Harv Bus Rev. 2011; 89(4): 48-55, 137. PMid: 21510518.

[78] Rogers E. Diffusion of preventive innovations. Addict Behav. 2002; 27: 989-93. http://dx.doi.org/10.1016/S0306-4603(02)0 0300-3 